(NASA-TM-X-72005) A FINTTE ELEMENT ANALYSIS OF FATIGUE CRACK CLOSURE (NASA) $34 \mathrm{p}$ HC $\$ 3.25$
N $74-32353$

Unclas 47743

\title{
A FINITE-ELEMENT ANALYSIS OF FATIGUE CRACK CLOSURE
}

by J. c. Newman, Jr.

Langley Research Center

Hampton, Virginia 23665

Technical Paper presented at the Eighth National Symposium on Fracture Mechanics, Providence, Rhode Island, August 26-28, 1974.

This informal documentation medium is used to provide accelerated or special release of technical information to selected users. The contents may not meet NASA formal editing and publication standards, may be revised, or may be incorporated in another publication.

NATIONAL AERONAUTICS AND SPACE ADMINISTRATION 


\begin{tabular}{|c|c|c|c|c|}
\hline $\begin{array}{l}\text { 1. Report No. } \\
\text { NASA TMX- } 72005\end{array}$ & \multicolumn{2}{|c|}{ 2. Government Accession No. } & \multicolumn{2}{|c|}{ 3. Fecipient's Cotalog No. } \\
\hline \multirow{2}{*}{\multicolumn{3}{|c|}{$\begin{array}{l}\text { 4. Title and Subtitle } \\
\text { A Finite Element Analysis of Fatigue Crack Closure }\end{array}$}} & \multicolumn{2}{|c|}{$\begin{array}{l}\text { 5. Report Date } \\
\text { SEPTEMBER } 1974\end{array}$} \\
\hline & & & \multicolumn{2}{|c|}{ 6. Performing Organization Code } \\
\hline \multirow{2}{*}{$\begin{array}{l}\text { 7. Author(s) } \\
\text { J. C. Newman, Jx. }\end{array}$} & & \multirow{2}{*}{\multicolumn{2}{|c|}{ 8. Performing Organization Report No. }} \\
\hline & & & & \\
\hline \multirow{2}{*}{\multicolumn{3}{|c|}{$\begin{array}{l}\text { 9. Performing Organization Name and Address } \\
\text { NASA Langley Research Center } \\
\text { Hampton, Virginia } 23665\end{array}$}} & \multicolumn{2}{|l|}{$\begin{array}{l}\text { 10. Work Unit No. } \\
505-02-31\end{array}$} \\
\hline & & & \multicolumn{2}{|c|}{ 11. Contract or Grant No. } \\
\hline & & & \multirow{2}{*}{\multicolumn{2}{|c|}{$\begin{array}{l}\text { 13. Type of Feport and Period Covered } \\
\text { Technical Memorandum }\end{array}$}} \\
\hline \multirow{2}{*}{\multicolumn{3}{|c|}{$\begin{array}{l}\text { 12. Sponsoring Agency Name and Address } \\
\text { National Aeronautics and Space Administration } \\
\text { Washington, D.C. } 20546\end{array}$}} & & \\
\hline & & & \multicolumn{2}{|c|}{ 14. Sponsoring Agency Code } \\
\hline \multicolumn{5}{|c|}{$\begin{array}{l}\text { 15. Supplementary Notes } \\
\text { Paper presented at the Eighth National Symposium on Fracture Mechanics, } \\
\text { August } 26-28,1974 \text {. }\end{array}$} \\
\hline \multicolumn{5}{|c|}{$\begin{array}{l}\text { 16. Abstract } \\
\text { Experiments have shown that fatigue cracks close at positive loads during } \\
\text { constant-amplitude load cycling. The crack-closure phenomenon is caused by residm } \\
\text { wal plastic deformations remaining in the wake of an advancing crack tip. The } \\
\text { present paper is concerned with the application of a two-djmensional, nonlinear, } \\
\text { finite-element analysis for predicting crack-closure and crack-opening stresses } \\
\text { during cyclic loading. } \\
\text { A two-dimensional finite-element computer program, which accounts for both } \\
\text { elastic-plastic material behavior and changing boundary conditions associated with } \\
\text { crack extension and Intermittent contact of the crack surfaces under cyclic loading } \\
\text { has been developed. An efficient technique to account for changing boundary con- } \\
\text { ditions was also incorporated into the nonlinear analysis program. This program } \\
\text { was subsequently used to study crack extension and crack closure under constant- } \\
\text { amplitude and two-level block loading. The calculated crack-closure and crack- } \\
\text { ppening stresses were qualitatively consistent with experimental observations. }\end{array}$} \\
\hline \multicolumn{2}{|c|}{$\begin{array}{l}\text { 17. Koy Word (Suggested by Author(s)) (STAR category underlined) } \\
\text { Finite element } \\
\text { Fatigue crack propagation } \\
\text { Structural mechanics } \\
\text { Materials (metallic) }\end{array}$} & 18. Distribution Stat & t & \\
\hline $\begin{array}{l}\text { 19. Security Cassif. (of this report) } \\
\text { Unclassified }\end{array}$ & \multicolumn{2}{|c|}{$\begin{array}{l}\text { 20. Security Classif. lof this page) } \\
\text { Unclassified }\end{array}$} & $\begin{array}{l}\text { 21. No. of Pages } \\
32\end{array}$ & $\begin{array}{l}\text { 22. Price* } \\
\$ 3.25\end{array}$ \\
\hline
\end{tabular}

\footnotetext{
-Available from $\left\{\begin{array}{l}\text { The National Technical Information Service, Springfield, Virginia } 22151 \\ \text { STIF/NASA Scientific and Technical Information Facility, P.O. Box 33, Coltege Park, MD } 20740\end{array}\right.$
} 


\section{A FINTTE-ELEMENT ANALYSIS OF FATIGUE CRACK CLOSURE \\ By J. C. Newman, Jr. \\ NASA Langley Research Center \\ Hampton, Virginia}

ABSTRACT

Experiments have shown that fatigue cracks close at positive loads during constant-amplitude load cycling. The crack-closure phenomenon is caused by residual plastic deformations remaining in the wake of an advancing crack tip. The present paper is concerned with the application of a two-dimensional, nonlinear, finite-element analysis for predicting crack-closure and crack-opening stresses during cyclic loading.

A two-dimensional finite-element computer program, which accounts for both elastic-plastic material behavior and changing boundary conditions associated with crack extension and intermittent contact of the crack surfaces under cyclic loading, has been developed. An efficient technique to account for changing boundary conditions was also incorporated into the nonlinear analysis program. This program was subsequently used to study crack extension and crack closure under constant-amplitude and two-level block loading. The calculated crackclosure and crack-opening stresses were qualitatively consistent with experimental observations.

INTRODUCTION

Until recentIy, fatigue-crack propagation was assumed to be directly related to the linear elastic stress-intensity factor [1] during cyclic loading. Implicit in this concept were the assumptions that only the tensile portion of the load cycle was effective in growing the crack, and that cracks close precisely at zero load. Elber [2-4] has shown experimentally that fatigue cracks 
close at positive loads during zero-tension constant-amplitude load cycling. He has indicated that fatigue-crack closure may be a significant factor in causing the stress-interaction effects on crack growth (retardation or acceleration) under general cyclic loading. He has also postulated that the crack-closure phenomenon is caused by residual plastic deformations remaining in the wake of the advancing crack tip.

Kobayashi, Chiu, and Beeuwkes [5], and Anderson [6] using the finiteelement method analyzed the steadily growing crack under a single monotonically increasing load. Since these investIgations did not consider cyclic loading, crack-closure effects were not accounted for in the analysis.

Newman and Armen [7], also using the finite-element method, analyzed an extending crack under cyclic loading and included the effects of crack closure. However, theirs was a general-purpose program which included a large number of options concerning the types of elements and the material stress-strain behavior and, consequently, required a large computer storage capability.

In the present paper, a more efficlent two-dimensional, nonlinear, finiteelement analysis [8] is presented, and used to investigate crack extension and crack closure in a center-cracked panel under cyclic loading. The panel material was assumed to be elastic-perfectly plastic. Both constant-amplitude and twolevel block loading were investigated. The crack-closure stresses, crackopening stresses, displacements, and residual stress distributions near the crack tip were determined as functions of applied atress.

SYMBOLS
a
Half-length of crack, $m$
[B]
Matrix relating total strains to nodal displacements, $\mathrm{m}^{-1}$
$\mathrm{C}, \mathrm{n}$
Material crack-growth constants 
Incremental applied load vector, $\mathbb{N}$

$\{d Q\}$

$\mathrm{dV}_{\mathrm{m}}$

$\{\alpha \epsilon\}$

$\left\{d_{e}\right\}$ $\left\{d \sigma^{\circ}\right\}$

$\left[\mathrm{D}_{\mathrm{e}}\right]$

g

$\mathrm{k}_{\mathrm{sx}}, \mathrm{k}_{\mathrm{sy}}$

$\left[\mathrm{K}_{\mathrm{s}}\right]$

$\left[\mathrm{K}_{\mathrm{e}}\right]$

\{P\}

(Q)

$\mathrm{R}$

S

$\mathrm{S}_{\max }$

$S_{\min }$

so

\{U\}

$u, v$

W

$\mathrm{x}, \mathrm{y}$

$\Delta a$

$\Delta K_{\text {eff }}$

$\Delta N$
Incremental load vector, $\mathrm{N}$

Differential volume of triangular element, $\mathrm{m}^{3}$

Incremental total strain vector

Incremental elastic stress vector, $\mathrm{N} / \mathrm{m}^{2}$

Incremental "initia. 1 " stress vector, $\mathrm{N} / \mathrm{m}^{2}$

Elasticity matrix relating stress to total strain, $\mathrm{N} / \mathrm{m}^{2}$

Relaxation parameter

Spring stiffness in $\mathrm{x}$ - and $\mathrm{y}$-direction, respectively, $\mathrm{N} / \mathrm{m}$

Diagonal matrix containing spring stiffnesses, $\mathrm{N} / \mathrm{m}$

Elastic stiffness matrix, $\mathrm{N} / \mathrm{m}$

Applied load vector, N

"Effective" plastic load vector, N

Stress ratio (ratio of minimum to maximum applied stress)

Applied gross stress, $\mathrm{N} / \mathrm{m}^{2}$

Maximum gross stress, $\mathrm{N} / \mathrm{m}^{2}$

Minimum gross stress, $\mathrm{N} / \mathrm{m}^{2}$

Crack-opening stress, $\mathrm{N} / \mathrm{m}^{2}$

Generalized nodal displacement vector, m

Displacements in $x-$ and $y$-direction, respectively, $m$

Total plate width, m

Cartesian coordinates

Incremental crack growth, m

Effective stress-intensity factor range, $N / \mathrm{m}^{3 / 2}$

Incremental number of cycles 
FINI'TE-ELEMMENT ANALYSIS

The elastic-plastic analysis of the center-cracked panel (Fig. 1) employed the fintte-element method and the initial-stress concept as described in [9]. The finite-element model, Figure 2, was composed of two-dimensional constantstrain triangular elements (unit thickness). In the initial-stress approach, the load-displacement relations for a discretized structure are written to include the effects of initial stresses, which are required in order to satisfy the yield criterion (von Mises) for an elastic-plastic material. These initial stresses produce effective plastic-load vectors which are applied to all elements which have become plastic and which maintain the permanent plastic deformation on those elements whlle the external loads are applied. The governing matrix equations for a discretized structure are reviewed only briefly here to demonsirate how the materlal nonlinearity is accounted for and what is required to treat crack extension and intermittent contact or separation of the crack surfaces.

Solution Procedure for Elastic-Plastic Structures

The application of the finite-element method to problems involving linearly elastic materials is straightforward because the material properties are constant and only one solution is required to obtain displacements for the elastic structure. However, for elastic-plastic structures the coefficlents in the stiffness matrix are functions of loading. Thus, the displacements are usually obtained by applying small load Increments to the structure and either updating the coefficients of the stiffness matrix or applying an "effective" plastic-load vector after each load increment. 
In general, the matrix equation which governs the response of a discretized stmucture under loads which cause plastic deformation is

$$
\left[K_{e}\right][U\}_{I}^{1}=\{P\}^{i}+\{Q]_{I-1}^{i-1}
$$

where $\left[K_{e}\right]$ is the elastic stiffness matrix, $\{U\}$ is the generalized nodal displacement vector, $(P\}$ is the applied load vector, and $\{Q\}$ is the "effective" plastic-load vector which accounts for elements in a plastic state. In the inltial-stress method, the solution to an elastic-plastic problem is obtained by applying a series of small load increments to the structure until the desired lood is reached $\left([P]^{1}=(P)^{1-1}+(d P\}\right)$. The superscrlpt $i$ in Equation (I) denotes the current load increment and $i-1$ denotes the preceding increment. After each load increment an 1terative process is required to stabilize the plastic-load vector. The subscript $I$ in Equation ( 1 ) denotes the current iteration and I - I denotes the preceding 1 teration. During the $1^{\text {th }}$ increment a purely elastic problem is solved and the increments in total strain \{dE\} and corresponding elastic stress $\left(d \sigma_{e}\right\}$ are computed from the displacements for every element. Because of the material nonlinearity the stress increments are not, in general, correct. If the correct stress increment for the corresponding strain Increment is $\{d \sigma\}$, then a set of body forces or plastic-load vectors (dQ) caused by the "initial" stress $\left(d \sigma^{\circ}\right\}\left(=\left\{d \sigma_{e}\right\}-(d \sigma\}\right)$ is required to maintain the stress components on the yield surface. The correct stress increment $\{d \sigma\}$ is computed from the equations.given in [9]. The plastic load increments are computed from

$$
(d Q]=\sum_{m=1}^{M} \int[B]^{T}\left[d \sigma^{a}\right\} d V_{m}
$$


where $M$ is the total number of elements, [B] Is the strain-displacement relationship, and the superscript $T$ denotes the matrix transpose. The integration is taken over the volume of each element and the summation is over all elements in the structure. For elements which are in an elastic state, $\left\{d \sigma^{\circ}\right\}=0$. The total plastic-load vector is then computed as

$$
\{Q\}_{I}^{i}=\{Q\}_{I-I}^{i-I}+\{\mathrm{d} Q\}
$$

At the second stage of computation the new force system $\{Q\}_{I}^{i}$ is added to the applied load vector and a new set of displacements is obtained. Again, some of the stresses are likely to exceed the yield criterion and a new set of plasticload increments is computed. The iteration process is repeated until the change in the plastic-load vector (Eq. (2)) is sufficiently small (0.1 percent of the final values was chosen here). Usually, 5 to 15 iterations are required to stabilize the plastic-load vector. However, for configurations which have large strain gradients, more iterations are required. For the cracked plate considered here and the particular element mesh used, 10 to 30 iterations were required. In order to reduce the number of iterations, a relaxation technique was incorporated into the nonlinear analysis program by using the equation

$$
\{Q\}_{I}^{i}=\{Q\}_{I-I}^{i-I}+g\{\mathrm{dQ}\}
$$

where $g$ is the relaxation parameter. Because the displacements from the preceding increment or iteration are used to compute the plast1c-load increment, the plastic-load vector is underestimated. Thus, the relaxation parameter is 
used to increase the plastic-load vector and, consequently, increase the rate of convergence. For the finite-element mesh used here, the displacements were found to converge roughly twice as fast using $g=2$ than using $g=1$ (usual value for the initial-stress method).

Solution Procedure for Changing Boundary Conditions

As previously mentioned, the finite-element analysis of an extending crack under cyclic loading must be able to account for changing boundary conditions during a specified load history. Usually, boundary conditions (free or fixed) in the finite-element method are satisfied by adding equations to, or deleting equations from, the overall system of equations. But the approach selected here was to connect two springs to each boundary node, as shown in Figure 3 . One spring was used to satisfy boundary conditions in the $x$-direction, and the other to satisfy conditions in the $\mathrm{y}$-direction. Therefore, all nodes in the system had two degrees of freedom. For free nodes, the spring stiffness, $\mathrm{k}_{\mathrm{sx}}$ or $\mathrm{k}_{\mathrm{sy}}$ ' was set equal to zero. For fixed nodes, the spring stiffness was assigned an extremely large value ( $10^{7}$ times the modulus of elastictty of the plate material). The spring stiffness was added to the diagonal coefficient in the conventional elastic stiffness matrix. The use of springs to satisfy boundary conditions was selected because an efficient technique to modify coefficients of the elastic stiffness matrix was incorporated into the nonlinear analysis program. This technique involved modifying the coefficients of the Cholesky decomposition [10] of the elastic stifeness matrix. The number of computer operations required to compute the modified Cholesky factors was of the order of $n^{2}$ ( $n$ was the total number of degrees of freedom). In contrast, the number of operations required to obtain the original Cholesky factors was of the order of $n^{3}$. A detailed discussion of the coefficlent-modification technique may be found in [8] or [10]. 
The coefficients of the elastic stiffness matrix are obtained from

$$
\left[K_{e}\right]=\sum_{m=I}^{M} \int[B]^{T}\left[D_{e}\right][B] d v_{m}+\left[K_{s}\right]
$$

where $\left[D_{e}\right]$ is the elasticity matrix and the diagonal matrix $\left[K_{s}\right]$ contains the elastic stiffness of the springs connected to the boundary nodes.

The procedure for treating the nonlinear material behavior in the presence of changing boundary conditions remains unchanged from that previously presented for an elastic-plestic structure, except that all nodal displacements along the crack line were monitored to determine whether the nodes are to be released (crack extends), to open (crack opening), or to close (crack closure).

To extend the crack, the crack-tip node was arbitarily chosen to be released at maximum load (the stiffness of the boundary spring was set equal to zero and the stiffness matrix was updated) and the crack tip was advanced to the next node. During the crack extension, the nodal force carried by the crack-tip node was released. To insure that the stresses and total strain increments in the adjacent elements satisfied the yleld condition and the PrandtI-Reuss flow rule, the iterative procedure, previously discussed, was used to redistribute the force prevlously carried by the broken node, and to stabilize the plastic-load vector.

During each load increment, the nodal displacements along the crack line were monitored to determine whether the crack surfaces had opened (positive displacement) or closed (negative displacement). If the crack surfaces had opened, the stiffness of the boundary spring was set equal to zero and the stiffness matrix was updated. If the crack surfaces had closed, the spring stiffness was set to the extremely large value and the stiffness matrix wos updated. 
APPLICATION OF THE FINITE-ELEMENT ANALYSIS TO CYCLIC CRACK EXTENSION

Elber [4], on the basis of fatigue crack-closure experiments with constantamplitude laading, proposed the following equation for fatigue-crack-propagation rates

$$
\frac{\Delta \mathrm{a}}{\Delta \mathrm{V}}=\mathrm{C}\left(\Delta \mathrm{K}_{\mathrm{eff}}\right)^{\mathrm{n}}
$$

where $C$ and $n$ are material constants and $\Delta K$ eff is the effective stressintensity factor range. He proposed that the effectlve stress-intensity factor range be calculated by

$$
\Delta K_{\text {eff }}=\Delta S_{\text {eff }} \sqrt{\pi a} \quad a
$$

where a is the half-length of the crack, $\alpha$ is a boundary-correction factor, and $\Delta S_{\text {eff }}$ is the effective atress range, given by

$$
\Delta s_{\text {eff }}=s_{\max }-s_{o} \text { for } s_{o} \geq s_{\min }
$$

where $S_{\max }$ is the maximum stress, $S_{m i n}$ is the minimum stress, and $s_{0}$ is the crack-opening stress. Thus, the crack is assumed to propagate only during that portion of the load cycle in which the crack tip is open. Equations (6)-(8) suggest, then, that the crack opening stress can significantly influence crack growth under both constant-and variable-amplitude loading.

The following sections give the results of applying the finite-element analysis to an extending crack under cyclic loading. The center-cracked panel, Figure 1, was subjected to either constant-amplitude or two-level block loading. 
In this study, no attempt was made to establish a failure criterion for crack growth. For any cyclic loading, the crack-tip node (A, B, ..., or F in FIg. 2) was arbitrarily chosen to be released at the maximum applied stress regardless of the magnitude of the applied stress and of any prior stress history. Thus, the model provides no direct information on the amount of crack growth per cycle; this information must be obtained from Equation (6). Instead, the analysis provides only the crack opening stress, $s_{0}$, to be used in Equation (8).

The finite-element idealization and the coordinate system used for the center-cracked panel are shown in Figure 2. The initial crack tip was located at node A (see Fig. 2), so that the initial crack half-length, $a_{i}$, was $27.3 \mathrm{~mm}$. The total panel width was $460 \mathrm{~mm}$. The elastlc-stress concentration (ratio of $\sigma_{\text {yy }}$ in the most highly stressed crack-tip element to the applied stress) was approximately 7 .

The panel material was assumed to be elastic-perfectly plastic with a tensile (and compressive) yield stress, $\sigma_{0}$, of $350 \mathrm{MN} / \mathrm{m}^{2}$ and a modulus of elasticity of $70,000 \mathrm{MN} / \mathrm{m}^{2}$. These properties are representative of an aluminum alloy material. The cyclic stress-strain curve assumed for this material is shown in Figure 4. The cyclic stress-strain curve was also taken to be the stabilized curve; that is, the stress-strain behavior was assumed to be unaffected by further cycling. (Crews [11] has shown that in some materials the local stressstrain behavior at a notch root stabilizes in approximately 10 cycles.) The solid line in Figure 4 shows the behavior under tensile loading. The dashed line indicates the typical behavior during unloading. The dash-dot line shows the behavior during reloading from a compressive plastic state. 


\section{Crack Extension Under Constant-Amplitude Loading}

Stress Level - The constant-amplitude loading applied to the center-crack panel is shown in Figure 5. The maximum gross stress was $0.30_{0^{\circ}}$ As the cyclic stresses were applied, the crack initially opened at an infinitesimal stress due to the assumption of no prior plastic deformation. The symbol $x$ indicates the point at which the most highly stressed crack-tip element initially yielded. At the maximum applied stress, node A (see Fig. 2) was allowed to displace (crack extension) and the crack tip advanced to node B. (Note that the crack extension increment, node $A$ to node $B$, is solely a consequence of the element mesh size used and does not imply a crack-growth law.) During unloading, node A was found to close at a positive stress (solid symbol) and was constrained against further motion. When the panel was reloaded, node A opened (open symbol) at a slightly lower stress than at which it had previously closed. Again, upon reaching the maximum stress, the next node (B) was also allowed to displace. During unloading, node (B) closed at a slightly higher stress than that at which node A had closed on the prevlous cycle. Further cycling and sequential release of nodes indicated approximately the same closure and opening stresses. The crack-opening stresses were approximately 30 percent of the maximum applied stress.

Figure 6 shows another cyclic load history investigated, for which $S_{\max }=0.4 \sigma_{0}$. Also shown are the calculated crack-closure and crack-opening stresses during constant-amplitude crack extension, indicated by the solid and open symbols, respectively. In this case, the contact (closure) stresses near node $A$ after the first cycles were so large that material behind the crack tip yielded in compression and the subsequent opening stress was considerably lower than the previous closure stress. The closure stress rapidly stabilized to 
approximately 40 percent of the maximum applied stress. The opening stress increased after each cycle until it converged to the previously established closure stress.

Because the crack-closure and crack-opening stresses are a function of the crack surface displacements, the variation of surface displacements with crack extension was investigated. The crack surface displacements for constantamplitude crack extension with $S_{\max }=0.4 \sigma_{0}$ are shown in Figure 7 . The displacement, $v$, in the $\mathrm{y}$-direction (Fig. 2) is plotted as a function of the coordinate location, $x$. The lowest curve shows the displacements at maximum stress with the crack tip located at node A (before crack extension). The other curves represent the crack-opening displacements at the maximum applied stress after each increment of crack extension. The sharp knee (slightly to the left of node A) in the displacement curves is an indication of the extent of severe plastic deformation.

To gain a qualitative understanding of the relationship between the residual plastic deformations near the crack tip and the crack-closure stresses, cracksurface displacements were computed for two similar configurations. The first configuration is a crack, with the tip initially at node $E$, being opened for the first time by the maximum applied stress $\left(S_{\max }=0.4 \sigma_{0}\right)$. The second configuration is a crack which was grown incrementally from node $A$ to node $E$ by cyclic loading (also with $S_{\max }=0.4 \sigma_{0}$ ). The results are shown in Figure 8 . The dash-dot curve is the surface displacements for the first configuration under the maximum stress. The solid curve is for the second configuration under the same maximum stress. The fully dashed curves show the displacements for the second configuration under a sequence of lower stresses for which the crack has closed successively from node $E$ to node $A$. 
The difference between the maximum surface displacements for the two configurations, as identified by the shaded region in Figure 8 , is a measure of the residual plastic deformations which are left in the wake of the advancing crack tip, and which Elber has postulated as the major cause of crack closure during unloading.

The displacement curves for lower stress levels further illustrate the crack-closure phenomenon. For example, a drop to $0.17 \sigma_{0}$ in applied stress caused the crack to close back to node D. Upon complete removal of the applied stress, the crack closed back to node A, but remained open to the left of node A. The atress distributions near the crack tip associated with these stages of unloading are shown in Figure 9. At the maximum applied stress, the near-tip stress $\sigma_{y y}$ (solid curve), reaches at plateau in front of the crack tip (characteristic of an elastic-perfectly plastic material). Because the local stresses are computed at the centroid of the elements $(\approx 0.3 \mathrm{~mm}$ from the crack surface), the stresses do not drop to zero immediately behind the crack tip. During unloading, the crack surfaces contact initially at node $D$ and the crack surfaces between nodes $D$ and $E$ begin to support compressive stresses, as illustrated by curves 3-5 of Figure 9 .

As further illustration of the influence of stress level on crack closure, Figures 10 shows the results of constant-amplitude crack extension with $S_{\max }=0.5 \sigma_{0^{\circ}}$ In contrast to the behavior at lower stress levels, this case required six crack-growth increments to stabilize the crack-opening stress. Again, the contact stresses near nodes $A, B$, and $C$ caused yielding in compression, as evidenced by the difference between the crack closure and opening stresses. In this case, the closure stress required a few cycles to stabilize. The opening stress increased with each cycle until it converged to the stabilized closure stress at approximately 50 percent of the maximum stress. 
Thus, for the cases considered here the magnitude of the maximum applied stress apparently established the crack-closure stress which was found to be higher for higher values of maximum applied stress. In addition, with a sufficient number of cycles, the opening stress converged to the closure stress. Stress Ratio. - To study effects of stress ratio on crack closure, calculations were made also for $R=0.5$ and $R=-1$. Figure Il shows a cyclic load history with $R=0.5$ and $S_{\max }=0.300_{0}$ Again, nodes $A, B, C$, and $D$ were released at succeeding occurrences of maximum stress. But in this case, the crack surfaces never closed. The solid symbols denote that the closure stress would have been approximately $0.08 \sigma_{0}$ had the panel been allowed to unload beyond the minimum stress. If crack propagation rates are related to the effective stress-intensity range (Eq. (6)), then, for stress ratios greater than approximately 0.3 and $S_{\max }=0.3 \sigma_{0}$, the present results suggest that crackgrowth rates should be independent of the closure or opening stresses. This inference is consistent with the experimental results obtained by Katcher [12] on 2219-T851 aluminum alloy where the crack-closure stress was found to be lower than the minimum stress when the stress ratios exceeded approximately 0.3 .

Figure 12 shows the crack-closure and crack-opening stresses for $R=-1$ and $S_{\max }=0.30_{0^{\circ}}$ During the compressive loading, all nodes along the crack line closed. The crack-opening stress (at node A) after the first cycle was considerably lower than the opening stress obtalned for the $R=0$ case (FIg. 5). This implies that the applied compressive stress caused the material near node A to yield in compression. However, after further crack extension, the closure and opening stresses stabilized at approximately the same level that had been observed previously at $R=0$ (Fig. 5). Therefore, according to Equation (6) the fatigue crack-growth rates for $R=0$ and $R=-1$ should be approximately 
the same. This inference is consistent with results obtained by'Hudson [13], who found very little difference between the crack-growth rates at $R=0$ and $R=-1$ in test of two different aluminum alloys.

Crack Extension Under Two-Level Block Loading

High-to-Low Loading - The high-to-low block loading is shown in Figure 13. The maximum stress $S_{\max _{1}}$ (first level) was $0.40_{0}$ and $S_{\max _{2}}$ (second level) was $0.3 \sigma_{0}$. The crack-closure stresses for the three cycles of $S_{\max _{1}}$ were 1dentical to those previously show in Figure 6 . At the maximum stress, $s_{\max _{2}}$, node D was allowed to displace. Durlng unloading, node $\mathrm{D}$ closed at a stress which was approximately 40 percent higher than the stabilized opening stress for $S_{\max _{1}}$ (dashed line). When the panel was reloaded, node D opened at about the same stress at which 1t had previously closed. During further cycling, the closure and opening stresses decreased after each cycle. If more than three cycles of $\mathrm{S}_{\max _{2}}$ were to be applied, the closure and opening stresses would be expected to converge to the dash-dot line (the stabilized opening stress for $\mathrm{S}_{\max _{2}}$; see Fig. 5) as the crack grew out of the material yielded by $S_{\max _{1}}$. Because the opening stresses for $\mathrm{S}_{\max _{2}}$ are considerably higher than the stabilized opening stress for $s_{\max _{2}}$ the crack-growth rates (computed from Eq. (6)) are expected to be considerably lower than if the three cycles $S_{\text {max }_{I}}$ had not been applied. This behavior has been experimentally observed and is referred to as crack-growth retardation or delay (see, for example [14]).

Low-to-High Loading - Figure 14 shows the low-to-high block loading, for which $S_{\max _{1}}=0.3 \sigma_{0}$ and $S_{\max _{2}}=0.4 \sigma_{0}$. The crack closure and opening stresses for $S_{\max _{1}}$ were identical to those shown in Figure 5 . When the stress first reached $\mathrm{S}_{\max _{2}}$, node $\mathrm{D}$ was released. During unloading, node $\mathrm{D}$ closed at approximately 40 percent of the maximum applied stress. At zero applied stress, the 
material near node D yielded in compression and the subsequent opening stress was lower then the previous closure stress. During further cycling, the closure stress remained nearly constant while the opening stress increased after each cycle. The opening stress had nearly converged to the stabilized opening stress after only three cycles of $\mathrm{S}_{\max _{2}}$, similar to the behavior observed in Figure 6 . Because the opening stresses for $\mathrm{s}_{\max _{2}}$ are lower than the stabilized opening stress, the crack-growth rates (computed from Eq. (6)) are expected to be higher than the crack-growth rates computed using the stabilized opening stress for $\mathrm{S}_{\max _{2}}$. This behavior in crack-growth rates has also been experimentally observed and is referred to as crack-growth acceleration [15].

CONCLUDING REMARKS

A two-dimensional (plane stress) finite element analysis which accounts for both nonlinear material behavior and changing boundary conditions under cyclic loading has been presented and used to study crack extension and crack-closure in a center-cracked panel. The finite-element model of the panel was assumed to be composed of an elastic-perfectly plastic material and was subjected to either constant-amplitude or two-level block loading.

Although the failure criterion used in growing the crack was arbitrary, the calculated crack-closure and crack-opening stresses under both constant-amplitude and two-level block loading were qualitatively consistent with experimental observations. The calculated crack-opening stresses, when used with Elber's crack growth equation, gave crack-growth-rate trends (retardation or acceleration) consistent with experimental measurements. Therefore, the finite-element analysis gives further insight into the mechanism of fatigue-crack growth during cyclic Ioading. 


\section{REFERENCES}

[1] Paris, P. C.; Gomez, M. P.; and Anderson, W.E: "A Rational Analyt1c Theory of Fatigue," The Trend in Engineering, University of Washington, Seattle, WA, Vol. 13, No. 1, 1961.

[2] Elber, W.: "Fatigue Crack Propagation," Ph.D. Thesis, University of New South Wales, Australia, 1968.

[3] Elber, W.: "Fatigue Crack Closure Under Cyclic Tension Loading," Engineering Fracture Mechanics, Vol. 2, No. 1, 1970.

[4] Elber, W.: "The Significance of Fatigue Crack Closure," ASTM STP-486, 1970.

[5] Kobayashi, A. S.; Chiu, S. T.; and Beeuwkes, R.: "A Numerical and Experimental Investigation on the Use of the J-Integral," Engineering Fracture Mechanics, Vol. 5, No. 2, 1973.

[6] Anderson, Hans: "The Steadily Growing, Elastic-Plastic Crack Tip in a Finite Element Treatment," Int. J. of Fracture, Vol. 9, 1973.

[7] Newman, J. C., Jr.; and Harry Armen, Jr.: "Elastic-Plastic Analysis of a Propagating Crack Under Cyclic Loading," AIAA Paper No. 74-366, Presented at the AIAA/ASME/SAE 15th Structures, Structural Dymamics and Materials Conference, Las Vegas, Nevada, Apri1 17-19, 1974.

[8] Newman, J. C., Jr.: "Finite-Element Analysis of Fatigue Crack PropagationIncluding the Effects of Crack Closure," Ph. D. Thesis, Virglnia Polytechnic Institute and State University, May, 1974.

[9] Zienkiewicz, 0. C.; Valliappan, S.; and King, I. P.: "Elasto-Plastic Solutions of Englneering Problems "Initial Stress," Finite Element Approach," International Journal for Numerical Methods in Engineering, Vol. 1, pp. 75-100, 1969. 
[10] Gill, P. E.; Golub, G. H.; Murray, W.; and Saunders, M. A.: "Methods for Modifying Matrix Factorizations," Computer Science Department, Stanford University, STAN-CS-72-322, pp. 18-24, 1972.

[11] Crews, J. H., Jr.: "Elastoplastic Stress-Strain Behavior at Notch Roots in Sheet Specimens Under Constant-Amplitude Loading," NASA TN D-5253, 1969.

[12] Katcher, M.: "Crack Growth Retardation Under Aircraft Spectrum Loads," Engineering Fracture Mechanics, Vol. 5, Dec. 1973.

[13] Hudson, C. Michael: "Effect of Stress Ratio on Fatigue-Crack Growth in 7075-T6 and 2024-T3 Aluminum-Alloy Specimens," NASA TN D-5390, 1969.

[14] Trebules, V. W.; Roberts, R.; and Hertzberg, R. W.: "Effect of Multiple Overloads on Fatigue Crack Propagation in 2024-T3 Aluminum Alloy," ASTM STP-536, 1972.

[15] Matthews, W. T.; Baratta, F. I.; and Driscoll, G. W.: "Experimental Observation of a Stress Intensity History Effect Upon Fatigue Crack Growth Rate," Int. Journal of Fracture Mech., 7 (1971). 


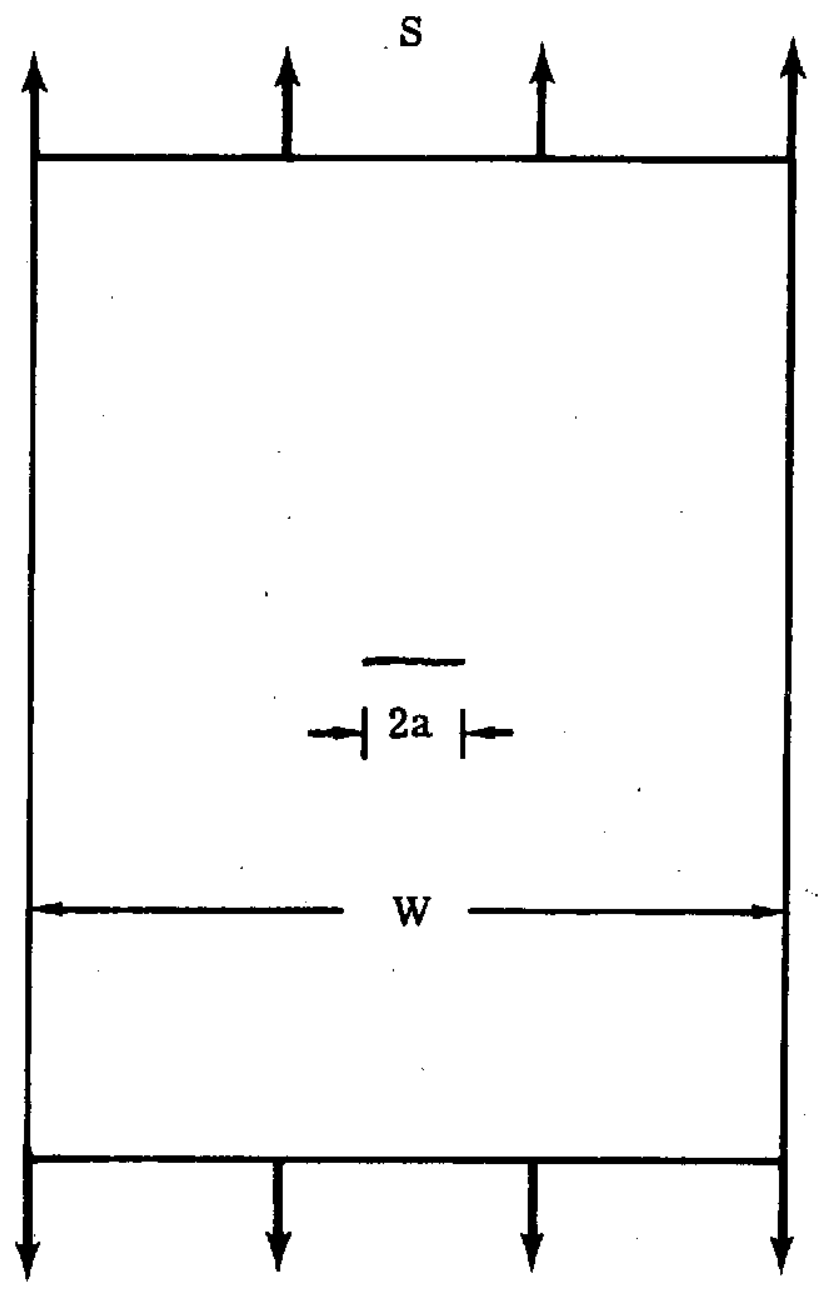

Figure 1. Center-crack panel subjected to uniform stress. 

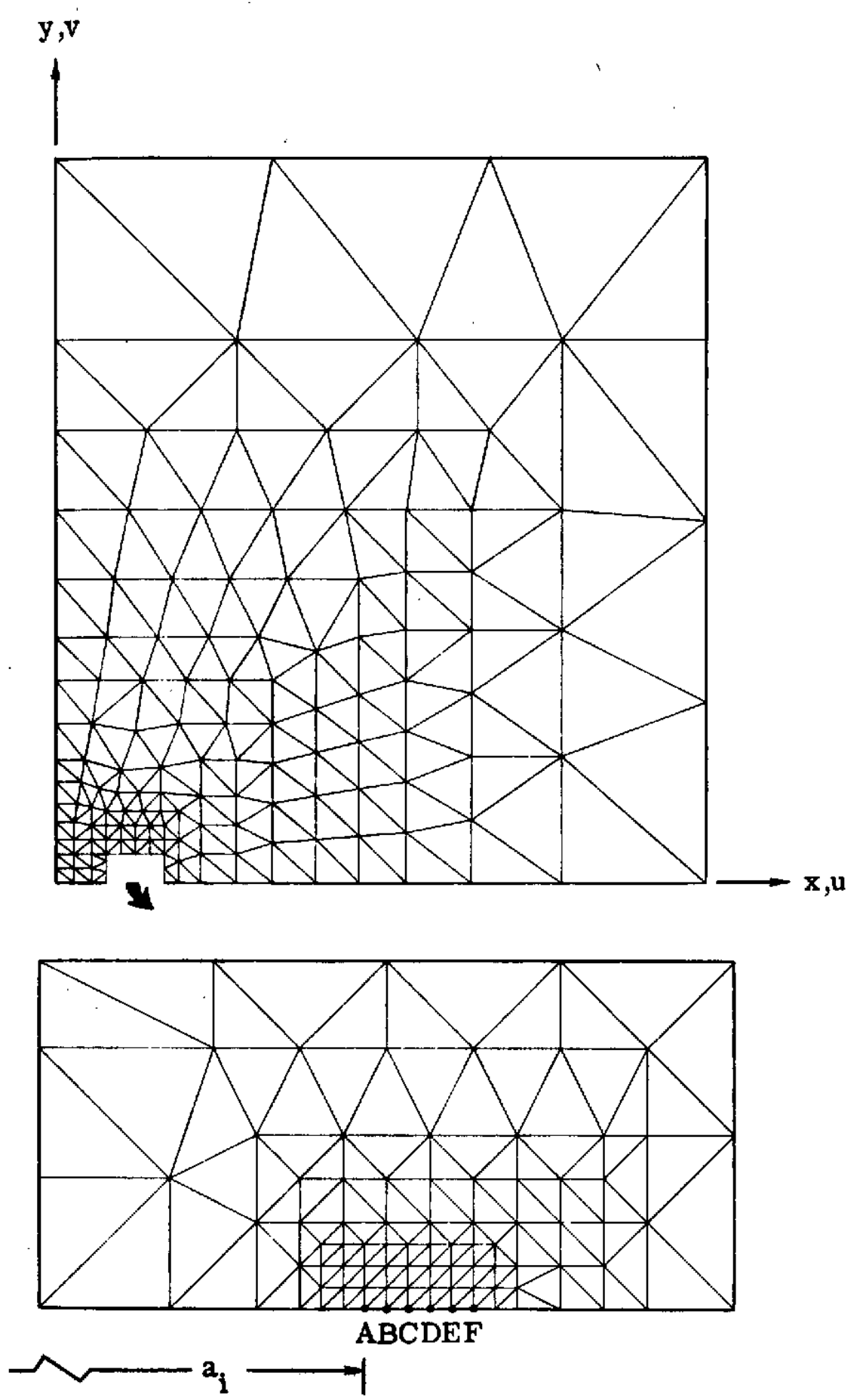

Figure 2. Finite-element idealization of the center-crack panel. 


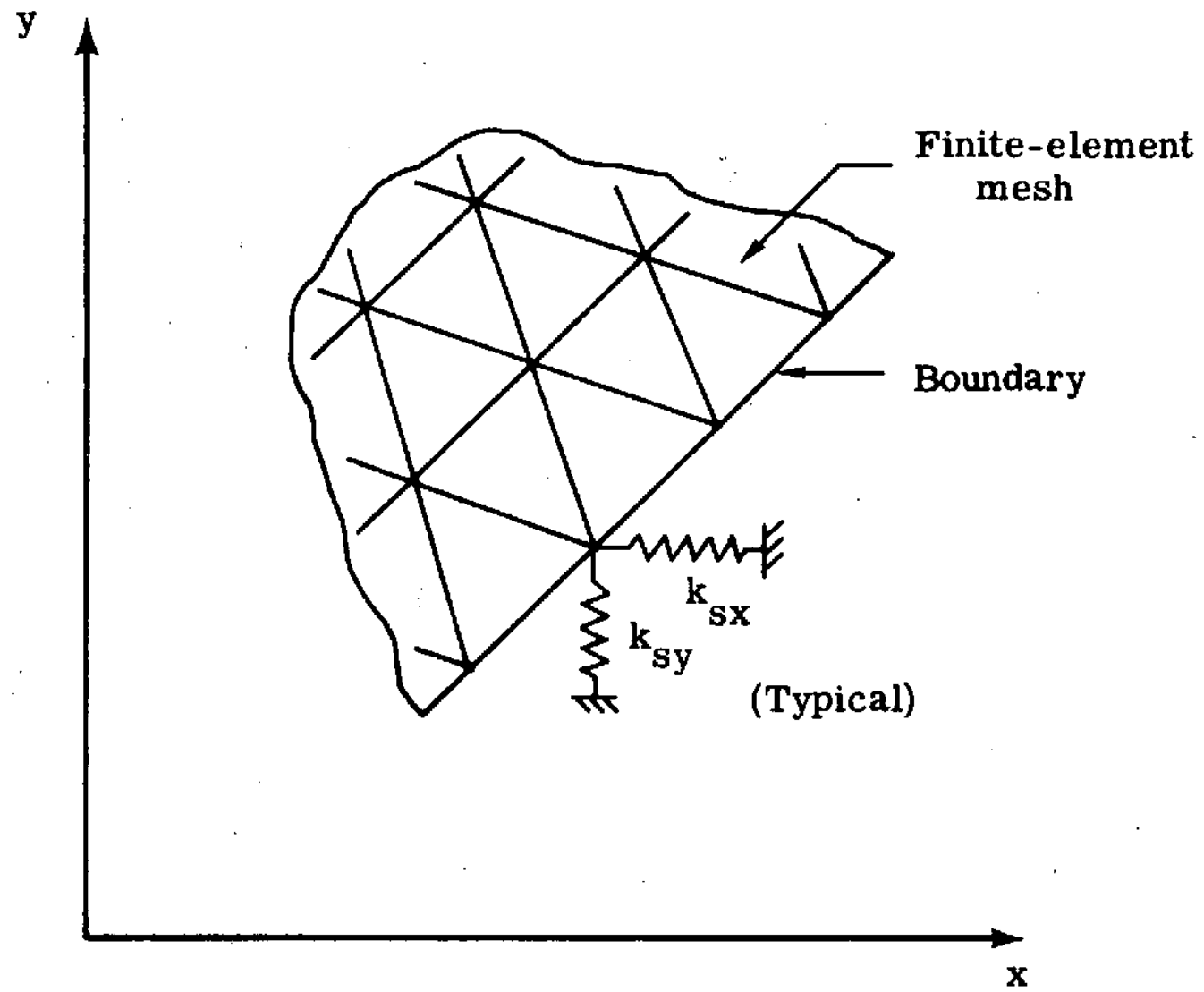

Figure 3. Springs connected to boundary nodes of a finiteelement mesh. 


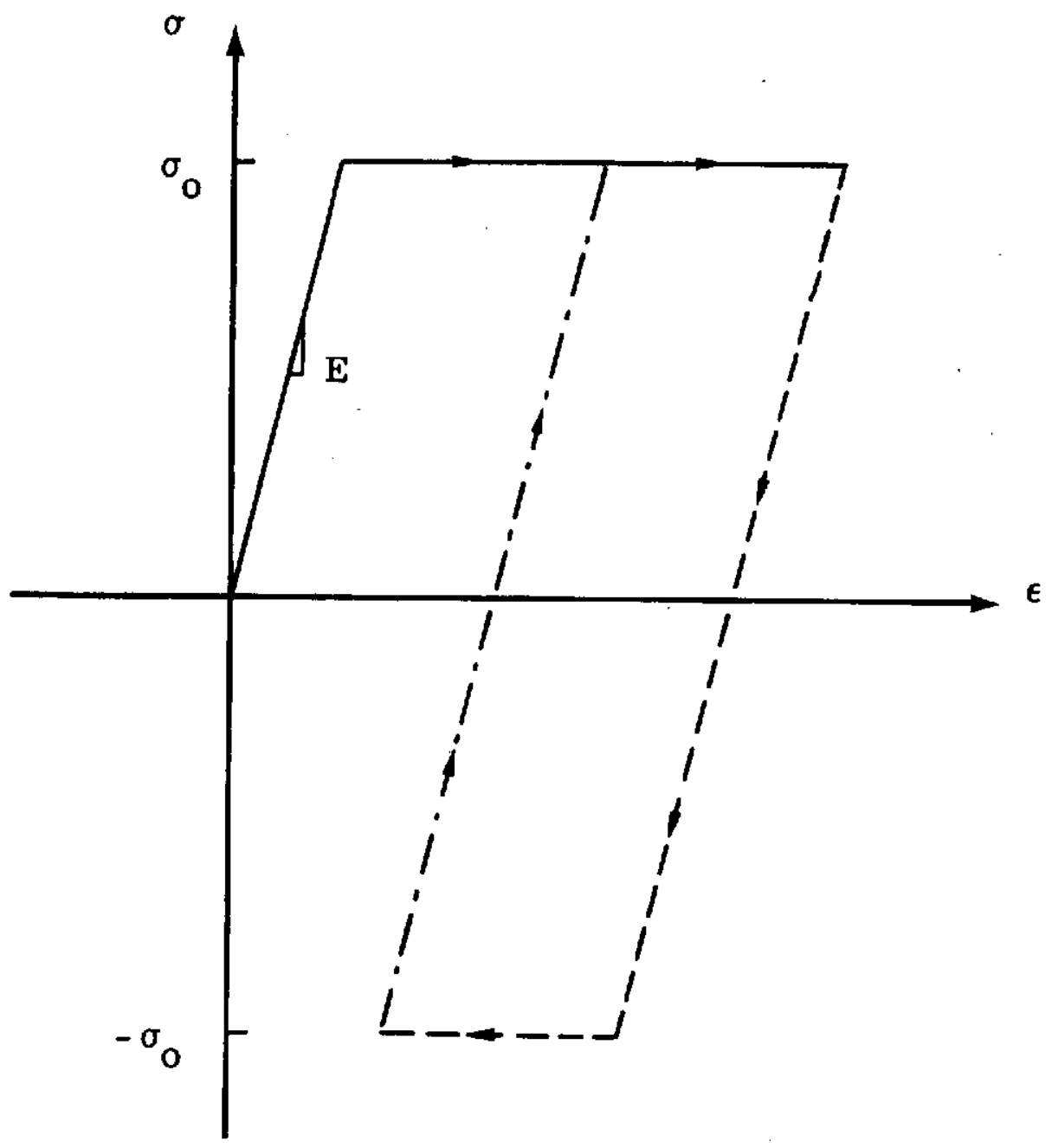

Figure 4. Cyclic stress-strain curve for an elastic-perfectly plastic material. 


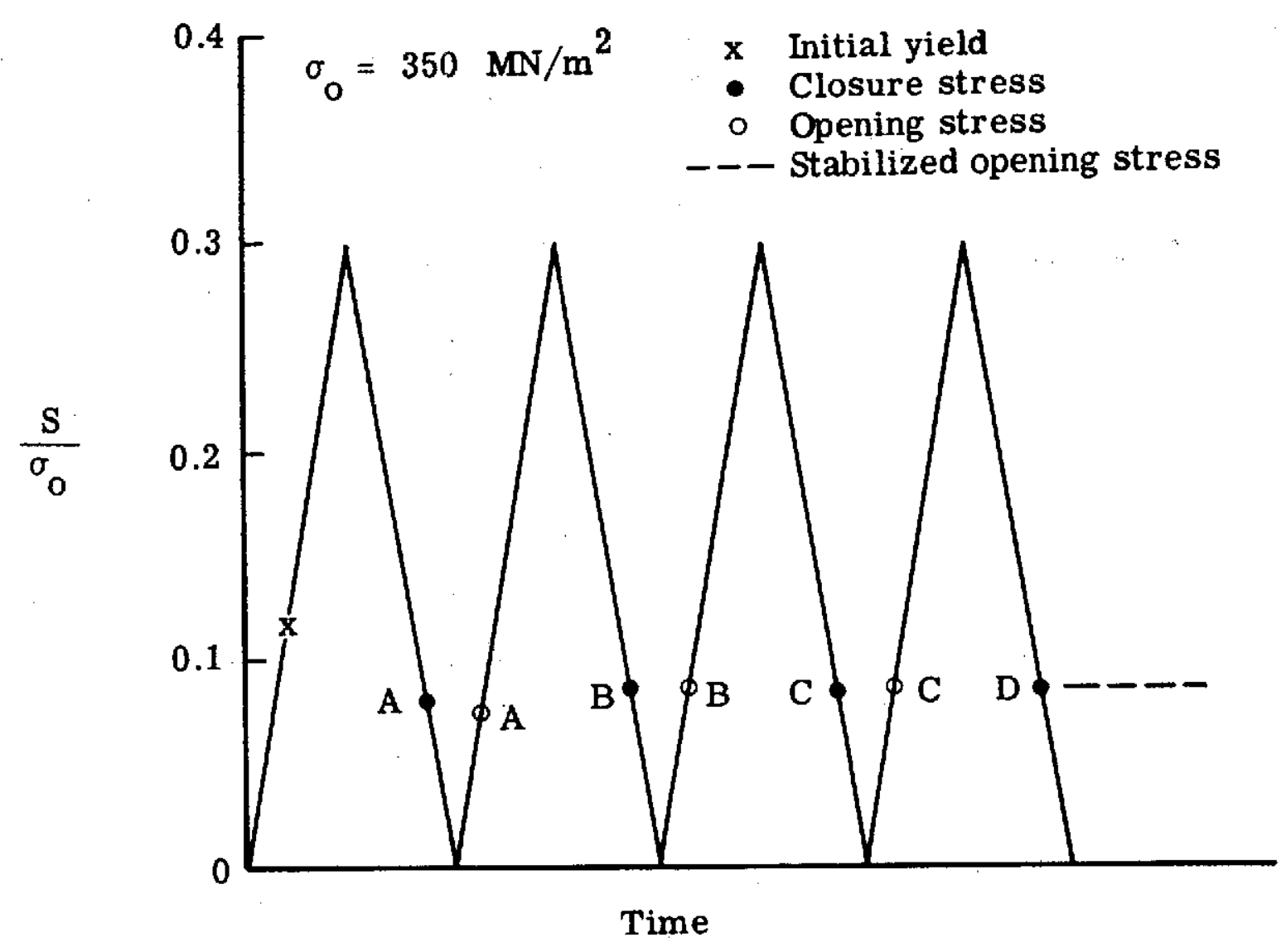

Figure 5. Constant-amplitude crack extension with $S_{\max }=0.3 \sigma_{0}$ and $R=0$. 


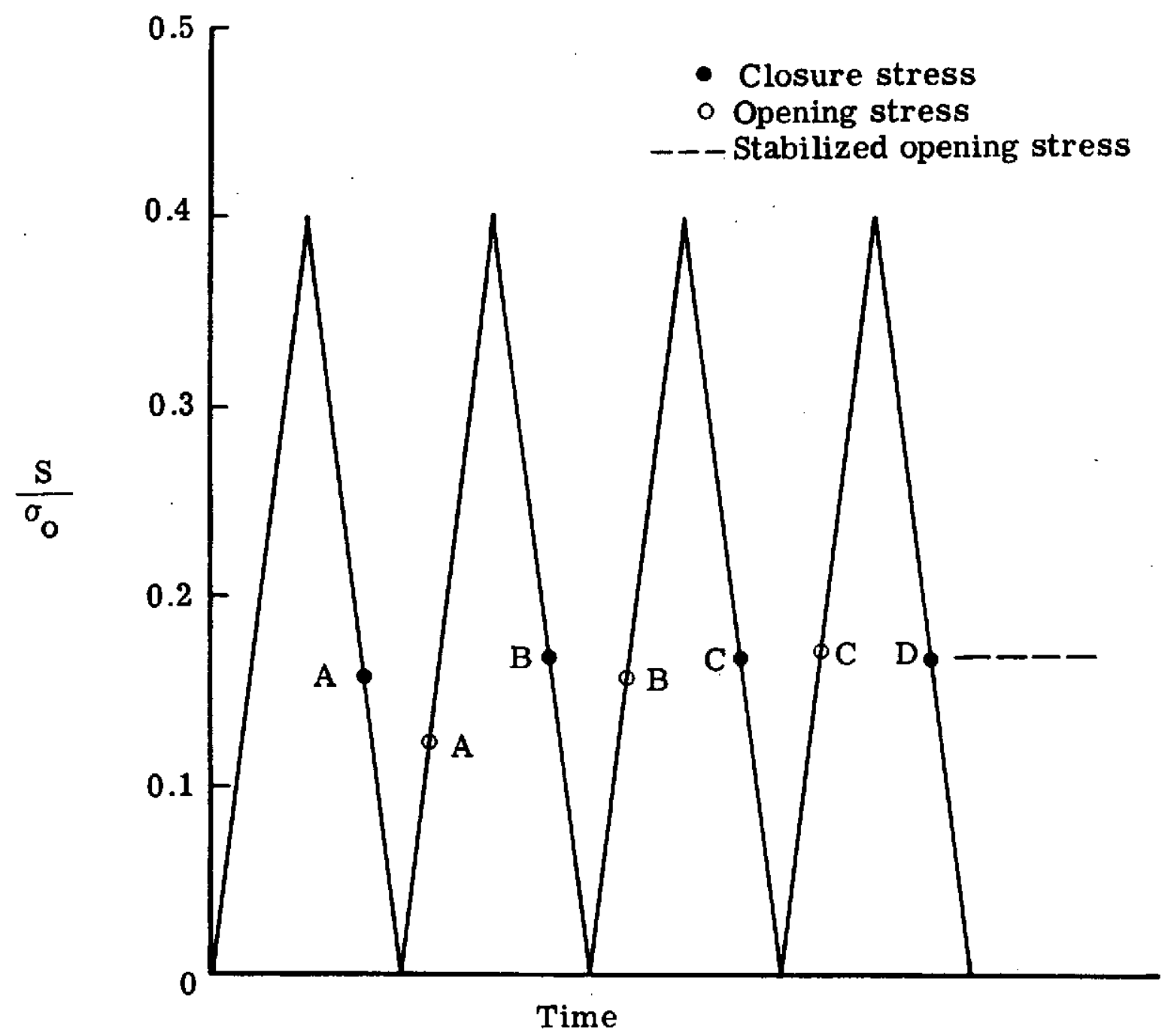

Figure 6. Constant-amplitude crack extension with $\mathrm{S}_{\max }=0.4 \sigma_{0}$ and $\mathrm{R}=0$. 
N

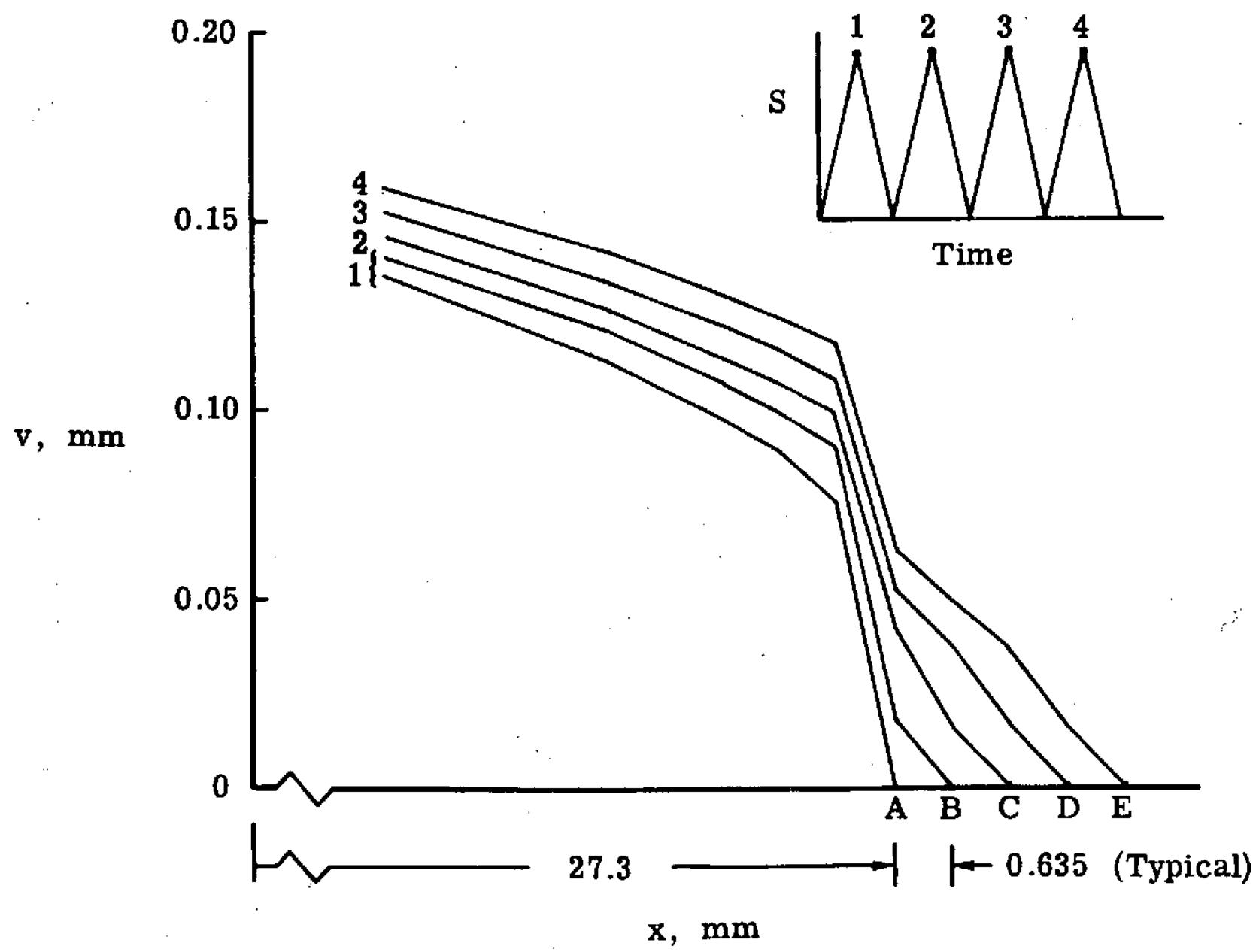

Figure 7. Crack surface displacements under constant-amplitude crack extension with $S_{\max }=0.4 \sigma_{0}$ and $R=0$. 


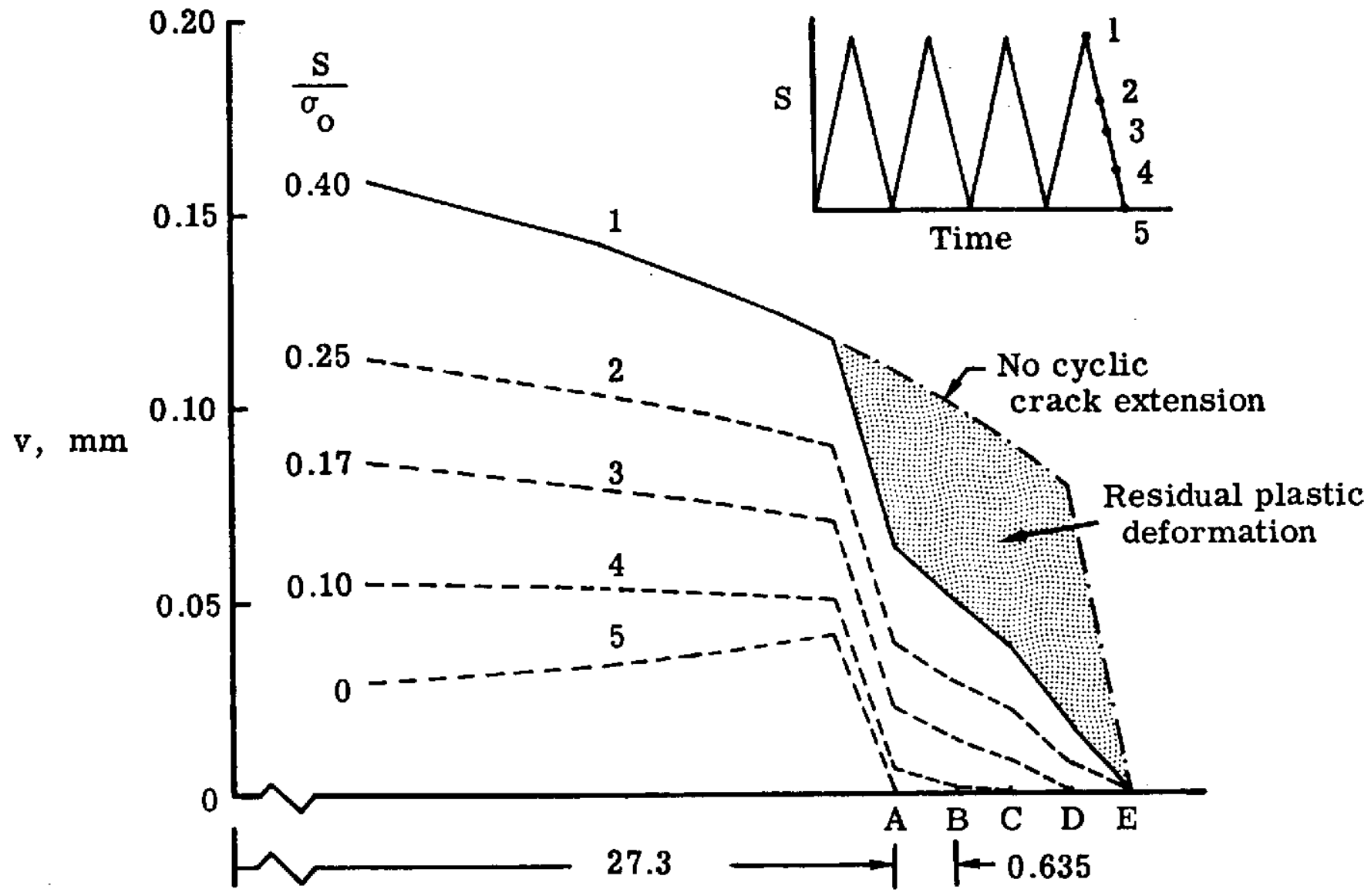

$\mathbf{x}, \mathbf{m m}$

Figure 8. Crack surface displacements during unloading after constant-amplitude crack extension ( $S_{\max }=0.4 \sigma_{0}$ ) with crack tip at node $\mathrm{E}$. 


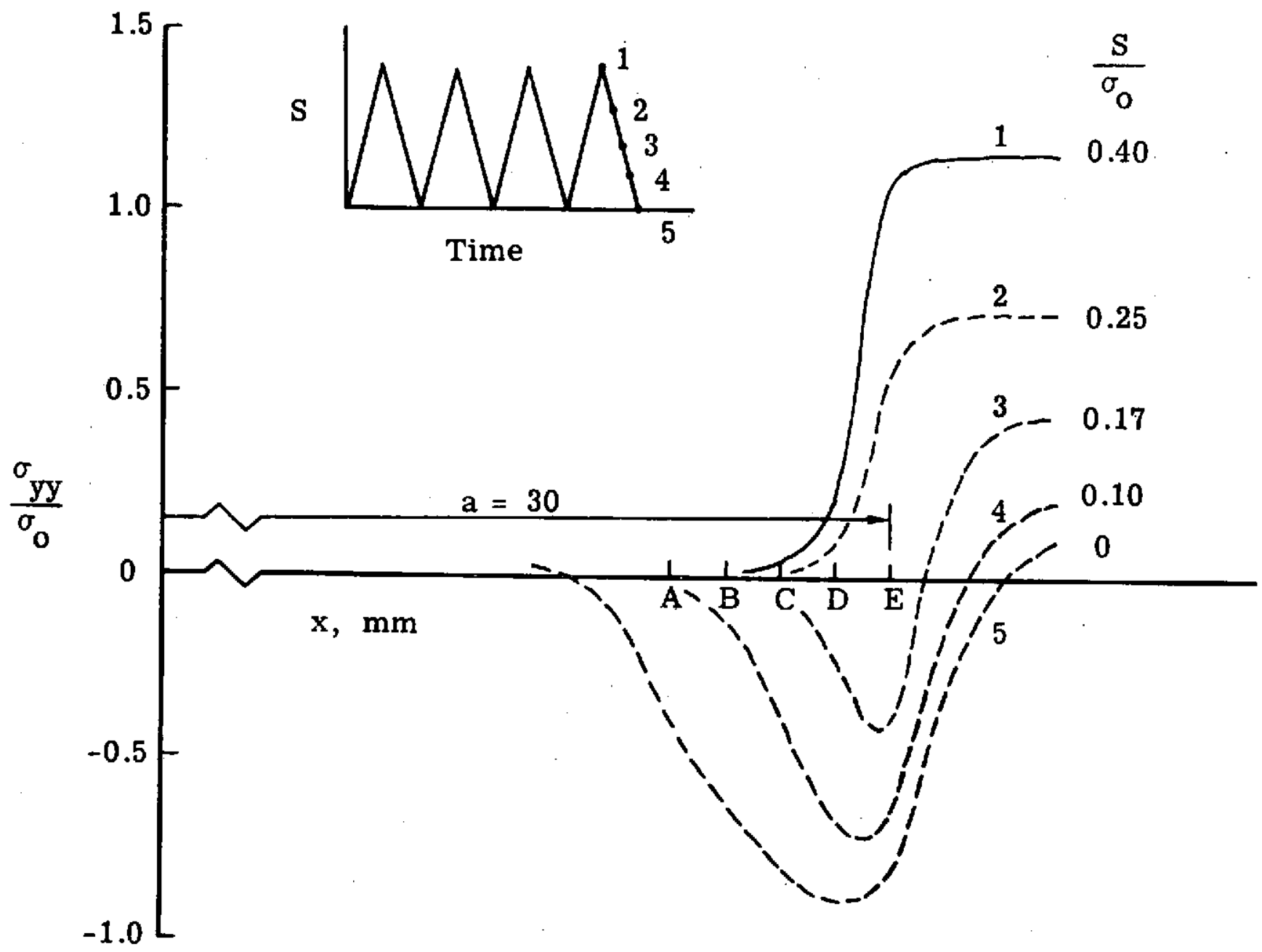

Figure 9. Local crack-tip stress distributions during unloading after constantamplitude crack extension $\left(S_{\max }=0.4 \sigma_{o}\right)$ with crack tip at node $\mathrm{E}$. 


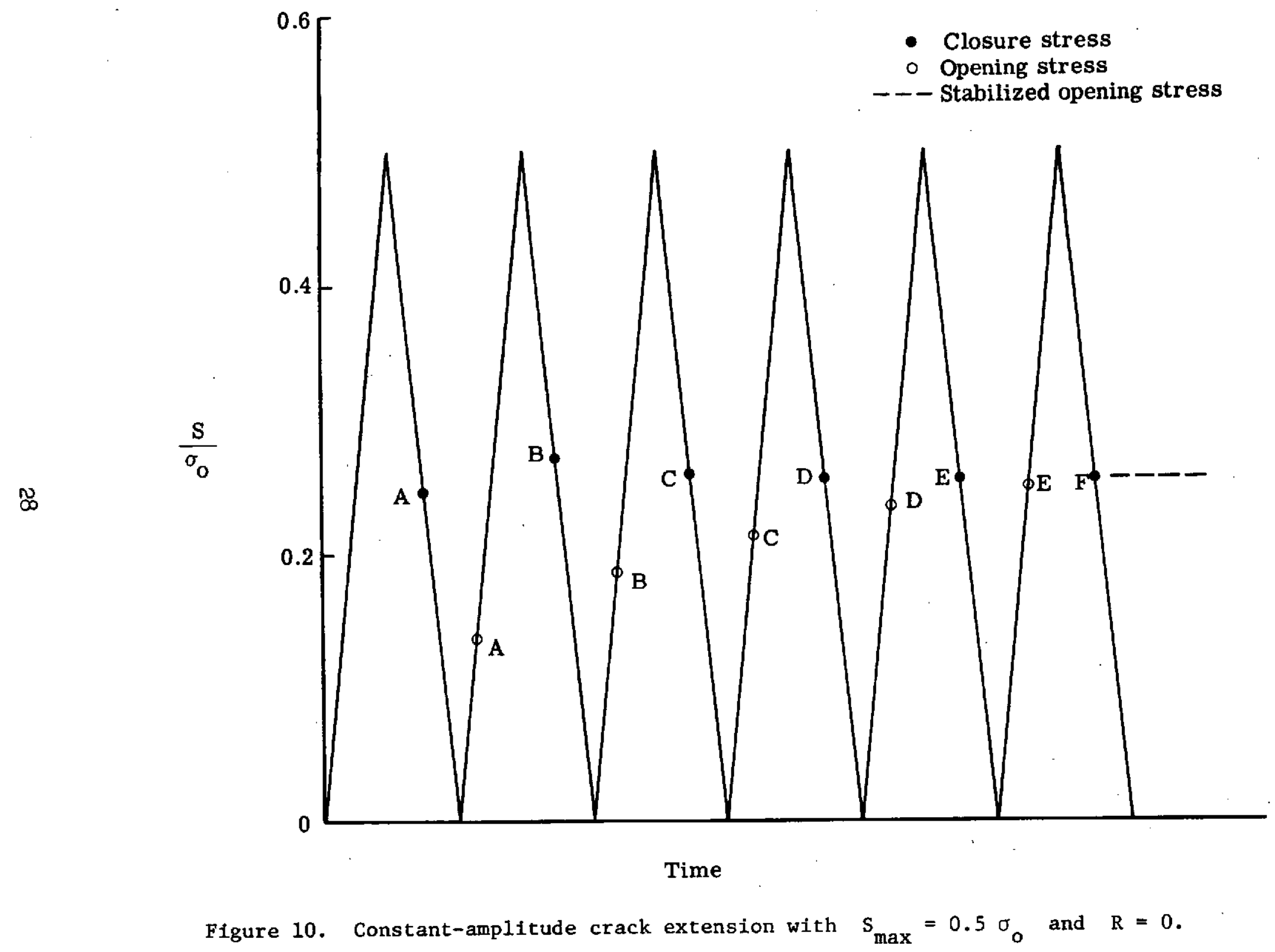




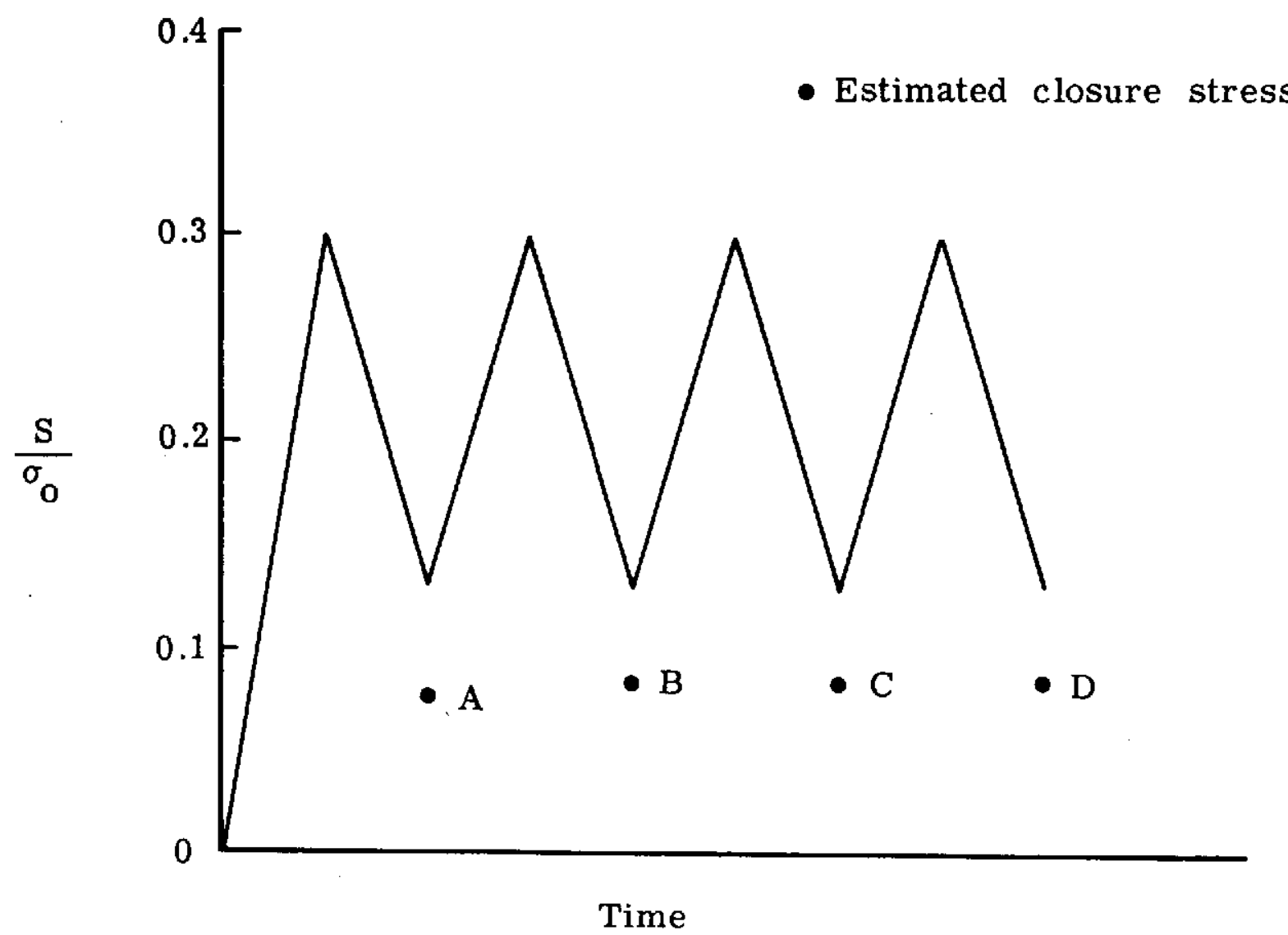

Figure 11. Constant-amplitude crack extension with $\mathrm{S}_{\max }=0.3 \sigma_{0}$ and $\mathrm{R}=0.5$. 


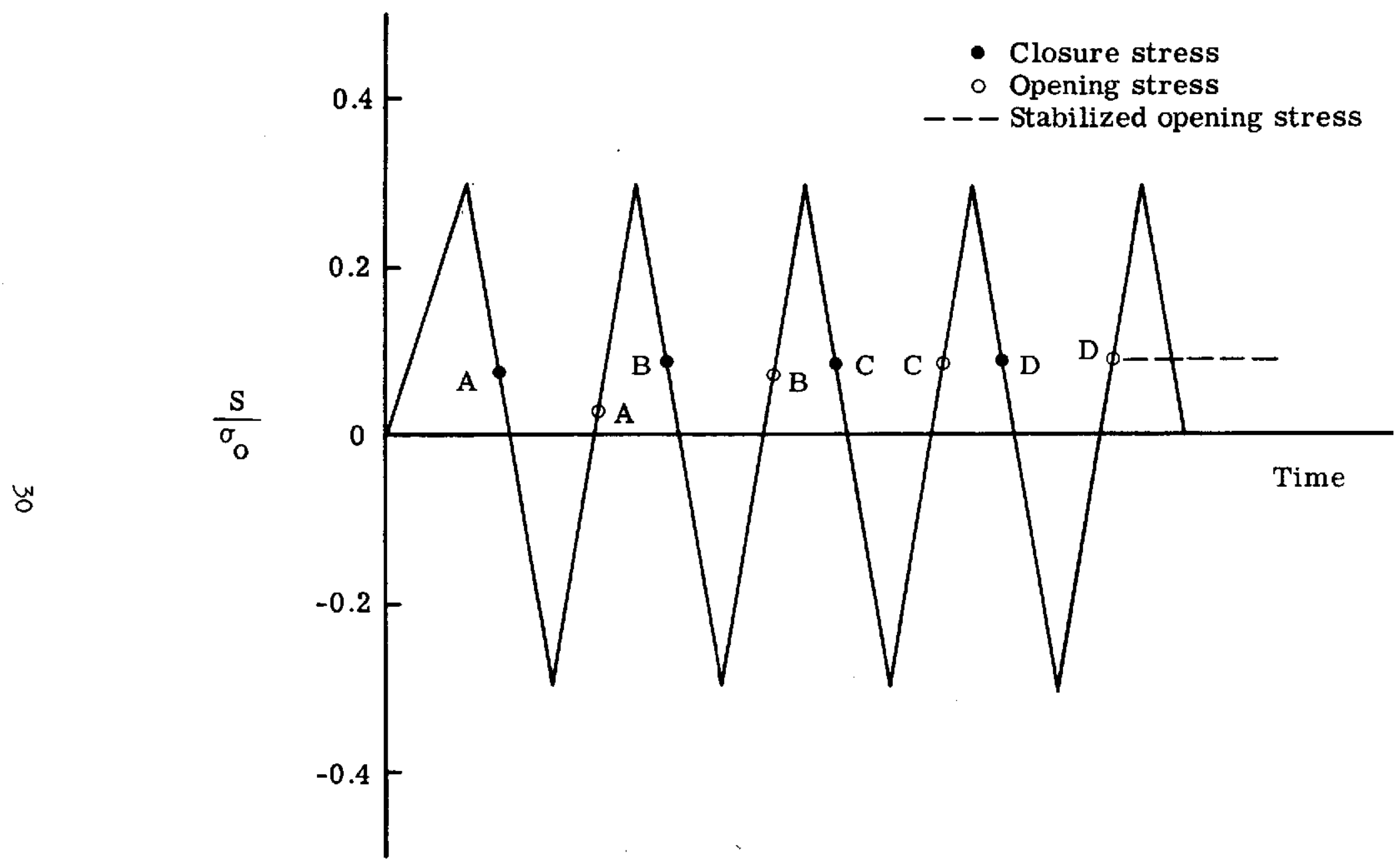

Figure 12. Constant-amplitude crack extension with $S_{\max }=0.3 \sigma_{0}$ and $R=-1$. 


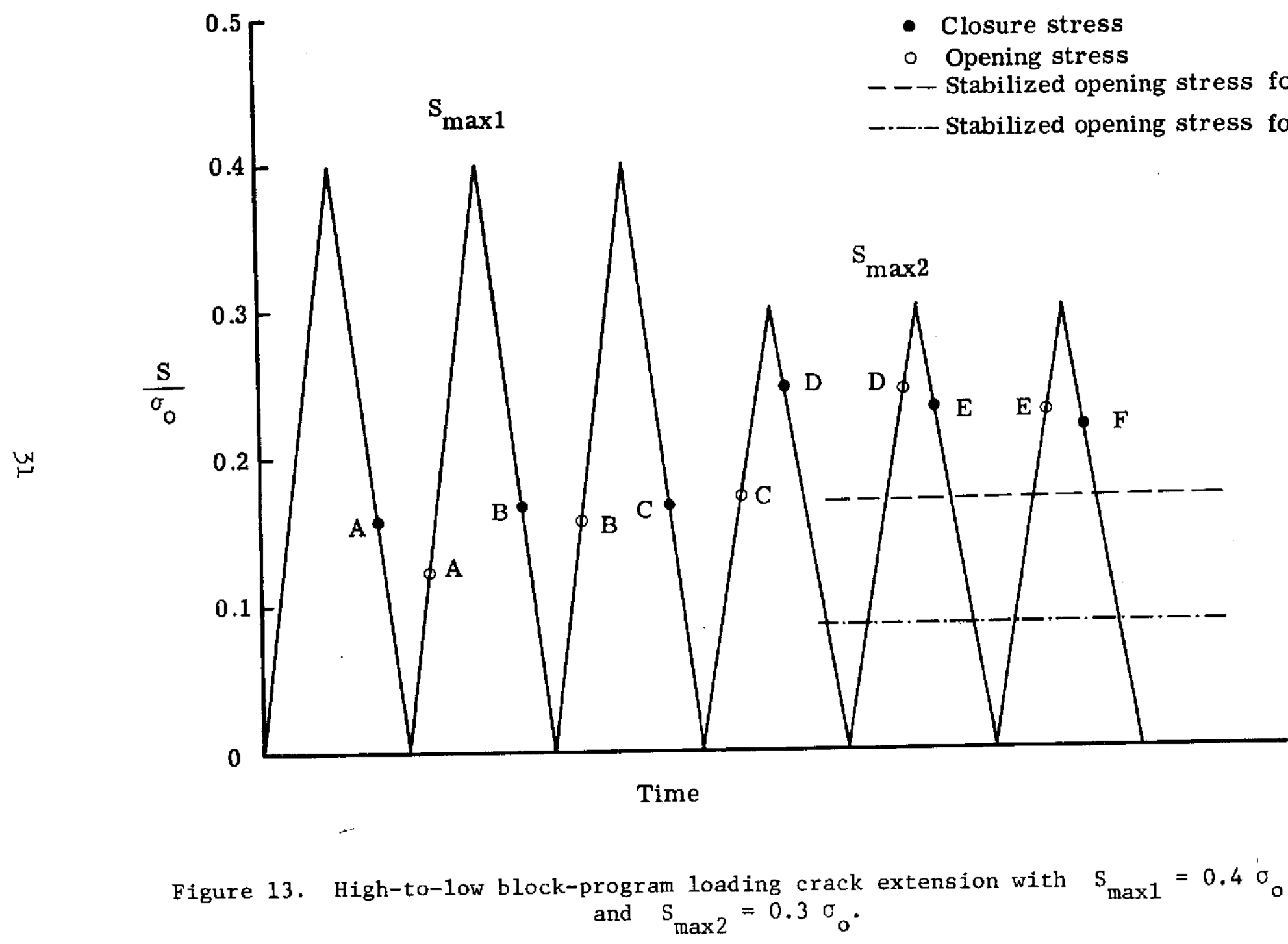




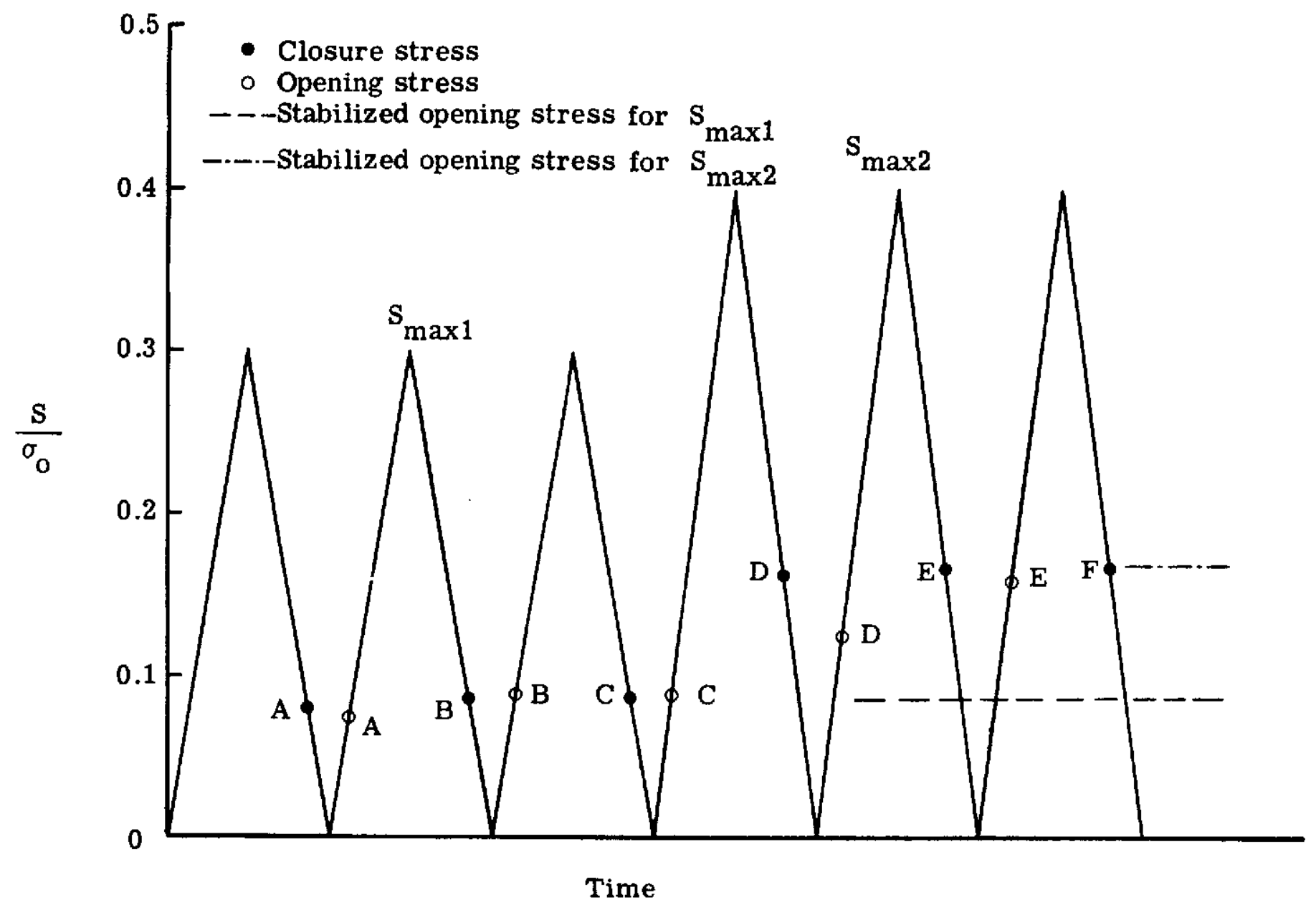

Figure 14. Low-to-high block-program loading crack extension with $\mathrm{S}_{\max 1}=0.3 \sigma_{\circ}$
and $\mathrm{S}_{\max 2}=0.4 \sigma_{0^{\circ}}$ 